\title{
Space for thought: designing for knowledge workers
}

\author{
C. Greene and J. Myerson \\ Helen Hamlyn Centre, Royal College of Art, London, UK
}

\begin{abstract}
Purpose - Generic use of the term "knowledge worker" has resulted in a generic approach to designing office environments for this group. The purpose of this paper is to probe the mobility patterns and motivations of knowledge workers in order to provide a classification of different types of knowledge worker.

Design/methodology/approach - The study was undertaken using a range of qualitative research methods including semi-structured interviews with 20 knowledge workers representing different levels of mobility and experience, ethnographic studies in a media company, real estate business and a public relations firm, and a user workshop. A novel drawing exercise was introduced to elicit responses during the interview process.

Findings - Four knowledge worker "character types" emerged from the research: the Anchor and the Connector, who are mainly office-based, and the Gatherer and the Navigator, who work more widely afield.

Research limitations/implications - This is a small study revealing characteristics particular to the participating individuals and organisations. However, it has wider implications in that the more complex set of requirements revealed by the project requires a more responsive and service-led approach to office design for knowledge workers and the development of new protocols of use within office space.

Originality/value - The originality/value lies in giving designers and facilities managers an insight into the different needs of knowledge workers, who are commonly treated as a homogeneous group. The typologies are an active tool for better brief-making in design for creative facilities.
\end{abstract}

Keywords Design, Productivity rate

Paper type Research paper

\section{Introduction}

As the world of work changes from an industrial economy to a knowledge-based one, the design of the office environment is struggling to adapt. The standard twentieth century office facility derived its template from the factory floor, from Fordism and Taylorism and from the close observation of process tasks and manual labour (Myerson and Ross, 2006). But time-and-motion studies within a supervised hierarchy are becoming far less relevant for much of the work we do today. Known as "knowledge work", this type of work depends less on following a repeating formula or script, and more on applying theoretical knowledge and learning in an unpredictable culture of collaboration, exploration, autonomy and initiative. This is a more creative way of working and, as such, it requires a more flexible design approach to facilities.

Much repetitive process work today is handled by computers or sent offshore to lower cost economies. Many office environments, particularly those associated with the creative industries, are no longer clerical paper factories but home to creative knowledge workers who struggle to cope with outmoded systems, structures and environments. During the twentieth century, productivity of the manual worker increased fifty-fold due to changes in factory and tool design. The US management

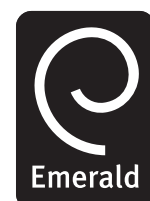

Facilities

Vol. 29 No. 1/2, 2011 pp. $19-30$

(C) Emerald Group Publishing Limited

0263-2772 
$\mathrm{F}$

$29,1 / 2$

20

expert Thomas Davenport is among those who suggest that knowledge workers in the twenty-first century will struggle to match those productivity gains. This is because too little is known about the nature of office facilities that make knowledge workers more productive - and about knowledge workers themselves (Davenport et al., 2002; Duffy, 2005).

In contrast with process or manual work, where the results can easily be measured by output over time, knowledge work is intangible and more difficult to map and assess. Knowledge work is mostly invisible, taking place, as Erlich and Bichard, 2008, have noted, inside the knowledge worker's head. It lacks, says Davenport, a twenty-first century equivalent of Frederick Taylor or Henry Ford to drive forward the design of the knowledge workplace.

In response to the rise of this more creative type of knowledge work, organisations have experimented heavily with costly office redesigns without learning much as a result. Davenport argues that "fad, fashion and faith drive most new work environments". It is our belief that so much design investment in office facilities has been wasted simply because organisations tend to lump knowledge workers into one homogenous group and assume they all work in the same way when there are very different types of knowledge worker with very different types of needs.

This paper describes a design research project undertaken by the Helen Hamlyn Centre at the Royal College of Art in order to learn more about workers in the knowledge economy and provide a classification of different types of knowledge worker. In this paper we suggest that only by understanding the movements and motivations of knowledge workers can office designers help them to be more productive, and we provide a set of typologies to aid understanding. The study, Space for Thought, conducted over a period of 12 months during 2008 and 2009, was supported by European furniture company Bene.

\section{Background}

The label "knowledge work" was first applied in 1960, simultaneously and independently by two American economists, Peter Drucker and Fritz Machlup. The first identified knowledge workers were doctors, lawyers, scientists and academics. The term was later extended by Drucker to include "knowledge technologists": computer technicians, lab analysts, paralegals, software designers - people whose work requires formal knowledge yet still contains elements of process work. Knowledge technologists are now among the fastest growing class of workers (Drucker, 1999) (see Figure 1).

Eurostat puts the number of people employed in knowledge-based industries in the UK at nearly half of the total working population. But with significant growth in investment in education over the last decade, and assuming technological growth continues at least the same rate as the past ten years, this figure is set to increase. Under pressure to reduce costs, yet aware of the value of teamwork and collaboration, many organisations have adopted the open-plan office as a simple one-size-fits-all design solution for all knowledge workers. As one facilities manager told us during the research:

We're trying to design a space that is middle ground and supports a variety of practices, but is standard.

This approach offers a low level of segmentation according to role or task and little choice for the individual, ignoring the creative and autonomous characteristics of 


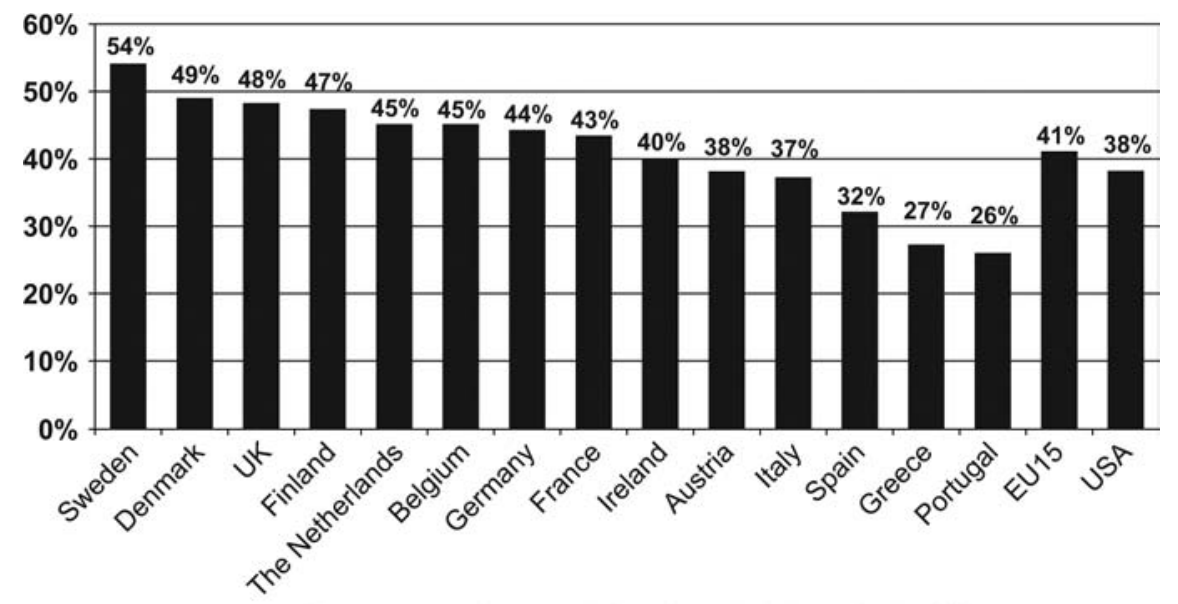

Employment in knowledge-based industries in 2005

Note: CEuropean Union (1995-2010)

Source: Eurostat
Space for thought

Figure 1. Employment in knowledge-based industries in 2005

knowledge work, whilst forcing a uniform solution on employers whose working patterns can vary enormously (Davenport et al., 2002). Our task was to find out what different generic types of knowledge workers exist and develop a better understanding of how they work.

\section{Methodology}

Literature search

A literature search was carried out to examine how previous studies on knowledge work have differentiated knowledge workers. Within communities of furniture designers and architects it has been common to speak about knowledge workers in terms of generations: Veterans, Baby Boomers, Generation X and Millenials (Steelcase, 2006). This is based on the notion that key differences exist in the work values and beliefs of people from different generations (Jorgensen, 2003). However research findings examining these differences have proved inconclusive (Wong et al., 2008) and in an era of growing knowledge about age discrimination somewhat age based determinist!

Others have looked to differentiate knowledge workers in terms of their activities. Dr. Francis Duffy, founder of the architectural practice DEGW, has looked at the degree of autonomy and interaction workers have with their colleagues and developed four typologies of organisation suitable for knowledge work: Den, Club, Hive and Cell (Duffy et al., 1998). Architectural and consulting firm, Gensler, has divided the day-to-day knowledge activities into four work modes with associated spaces, "socialise", "focus", "collaborate" and "learn" (Gensler, 2008). However, both of these examples resulted in spatial typologies, which, provide us with a limited viewpoint of the person who is actually doing the work within the space.

Technology usage has been adopted as another differentiating factor, as it has been common practice to ply knowledge workers with new technology tools such as laptops 
$\mathrm{F}$

$29,1 / 2$

22

and personal digital assistants in the information age (Davenport, 2005). But this approach can be limiting as the choice of technology is influenced by many stronger factors; these include mobility, which dictates certain requirements and influences our choices in relation to the technologies we choose to carry around with us (Veda, 2006). Similarly the extent of a knowledge worker's mobility has an effect on the way they use the office and subsequently, their needs in the workplace. An individual of high mobility who drops into the office for a single hour-long visit every week has very different needs to an individual of low mobility who is in the office eight hours a day, five days a week. Thus our inquiry became focused on how the knowledge worker interacts with the office building and for how long.

\section{User research}

The qualitative research was run in two stages. A first stage of in-depth user interviews was carried out to inform a conceptual framework, generating scenarios for four types of knowledge worker. These typologies were then tested in a second round of research, which included a further set of interviews, ethnographical research and user workshops.

A total of 20 people took part in the interviews, a broad range of participants was chosen to provide a spectrum of mobility, age and working experience. The age range spanned from 27 to 65, and the gender breakdown was eight women and 12 men. Participants were visited in their workplace and two-hour, semi-structured interviews were conducted with each respondent. The interviews explored work patterns, use of the office space, preferred work tools and alternative working environments.

\section{Graphic tool}

In each interview a simple graphic research tool was introduced to engage participants in thinking about how they used the office building. Each was presented with a grey box on a piece of paper, the box representing the office building, and invited to describe their mobility in relation to the office by drawing their movements in and around the box. This drawing technique proved effective in encouraging participants to describe their working patterns and habits in ways that would be hard to capture in words (see Figure 2).

\section{Ethnographic studies}

To expand upon and interrogate initial findings, ethnographic studies were carried out in three different organisations, a media company, a real estate business and a public relations firm. At each of these sites people were observed and photographed over several hours of the working day. The media company (the BBC Media Centre in London) was used as the main case study for the project with visits over the course of a week and five expert interviews held with key decision-makers including human resources, facilities management, buildings management and change management.

\section{User workshop}

Finally our results were tested in a workshop, to which 15 knowledge workers of different ages attended. These people, all new participants and representing the four typologies we had generated, were asked to map their work patterns and their associated needs to deepen insights arising from the study. 


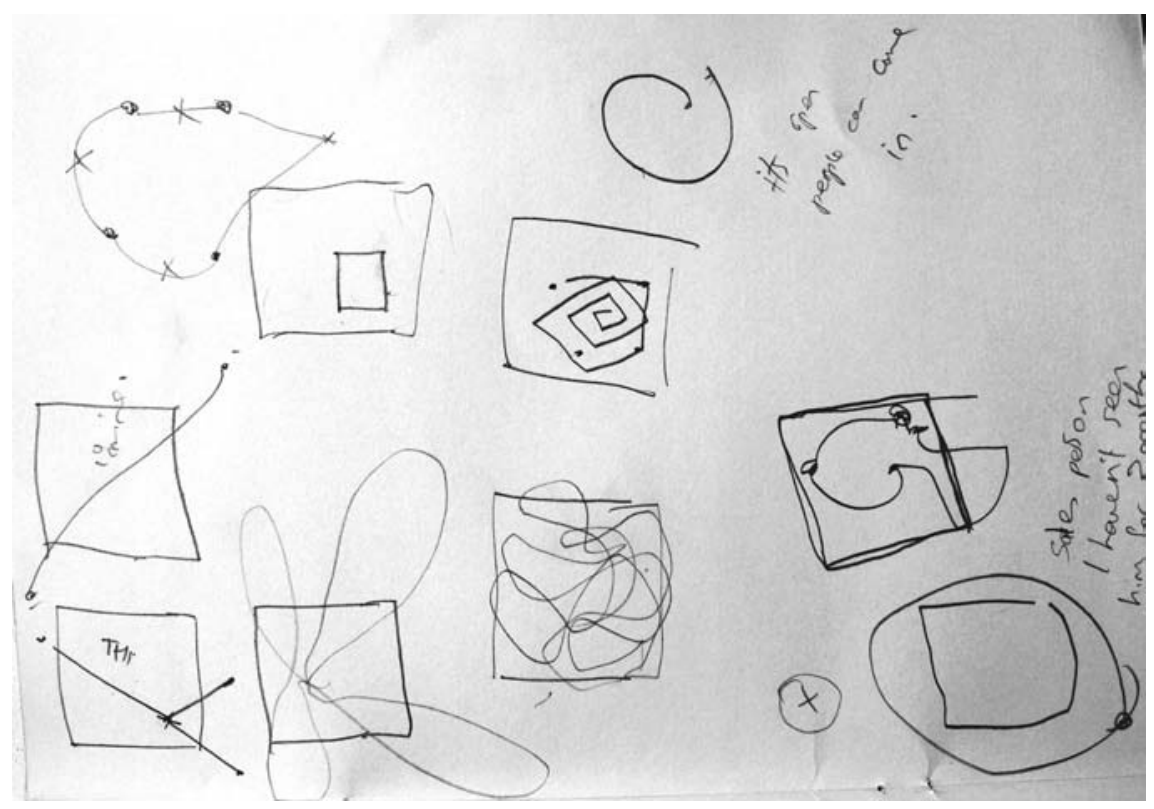

\section{Findings and outcomes}

The graphic tool used during the interviews captured how users perceived their pattern of work to be. The resulting drawings could be plotted along a scale of mobility from low to high representing a complete spectrum of knowledge worker. These were interrogated during an expert workshop to which six experts in the fields of anthropology, design, and the workplace attended. Four key points, equi-distant along the scale, were selected from the scale as a measure of the mobility of the knowledge worker at that point.

Four key types of knowledge worker emerged from the research, each defined along a scale of mobility from low to high. Many more can be selected along different increments of this scale, but these four were chosen to represent knowledge workers sufficiently different from each other that, in the consideration of their needs, they can be said to offer a balanced study of the knowledge worker group as a whole (see Figure 3).

\section{The Anchor}

The Anchor is the iconic sedentary office worker, someone who is reliably in the office every day and likely to be found at their desk during this time. While the Anchor can enjoy seniority as a hub figure within the organisation, most tasks are desk based and movement is limited to the areas around the workstation with journeys made to other functional spaces such as the restaurant or a meeting room. As a consistent presence in the office, the Anchor is the person that others go to in order to get information; hence they have a vital role in knowledge transfer within an organisation. In the division of tasks, Anchors prefer to organise their day into clearly defined times for social activity, informal collaboration, formal collaboration and solo activity. 
$\mathrm{F}$

$29,1 / 2$

24

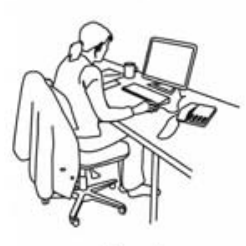

Anchor

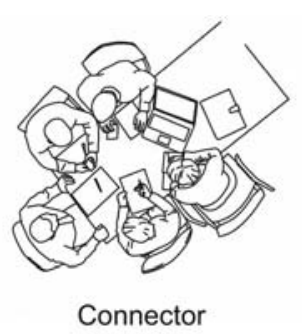

Connector

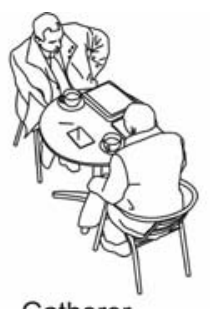

Gatherer

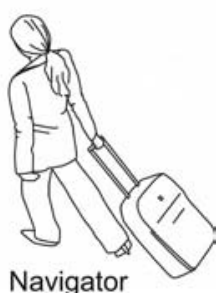

Navigator

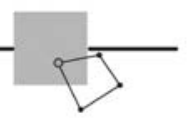

high mobility

Figure 3.

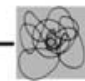

low mobility

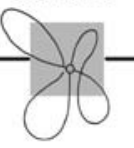

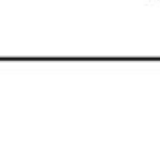

Participants who conformed to the Anchor typology described their desk as 'an extension of home'. A sense of ownership combined with the ritual of arriving to the same space each day was very important to them:

I like the ritual, some of it is about being near to the people I need to liaise with, some of it is about the welcome familiarity of the space.

Until recently, office furniture manufacturers have concentrated their products on this way of working. The needs for comfort have been met with ergonomic desks and chairs. However the Anchor maintains an uneasy relationship towards open plan space within which they are usually situated. Most of their tasks involve focused concentration and they often struggle in a noisy environment:

Ambient noise and phone calls are a problem. If I want a level of concentration I will put my iPod on which helps knock out the noise and stops people coming to talk to you (see Figure 4).
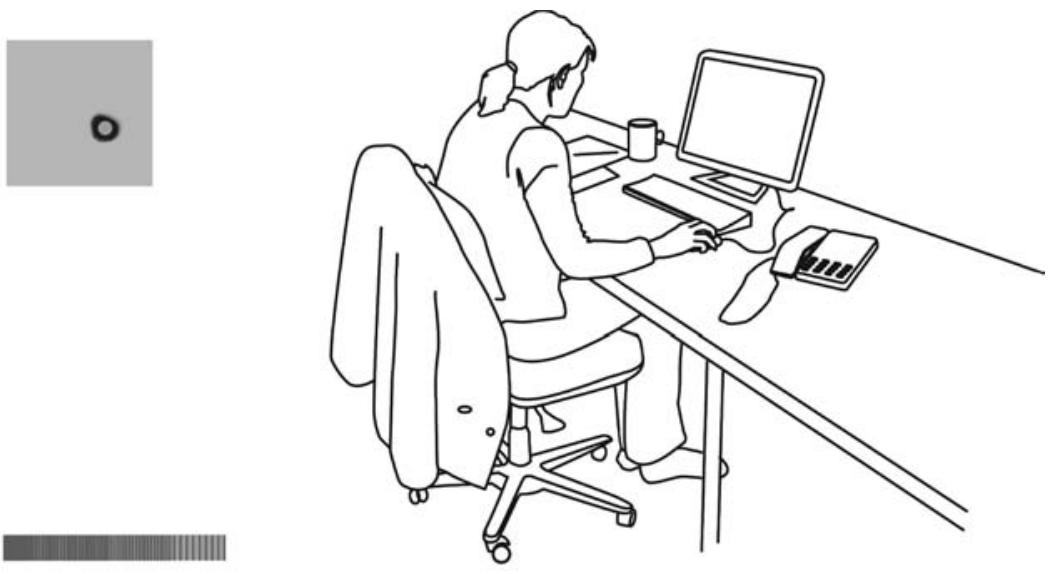

Figure 4 .

anchor

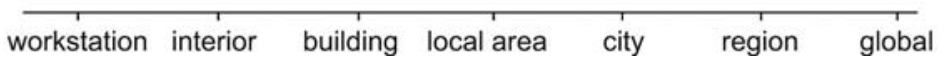


The Connector

The Connector is the 'needle and thread' within an organisation. They typically spend half of their time in different places around the building: in meeting rooms, in the café or at colleagues' desks. They leave their jacket over the back of their chair and are gone - and they may be mistaken for not doing any work at all. The Connector depends on interaction with people from different departments and across different sections of the company, but these interactions remain focused internally within the office building. A typical Connector would be the R\&D manager of an industrial company - with their job emphasis on growing an innovation culture throughout the company, effective communications between departmental managers and the production line is crucial.

Over the past ten years there has been a greater appreciation of the social aspects of work, with the emphasis of office design moving to one that fosters communication and collaboration, much to the benefit of our Connector:

The key for me is having alternatives - open plan, offices, booths, cafés. It's an ever-changing environment and that's why I like it.

But while the office environment has shifted towards greater social interaction, the design of these spaces has been compromised by the belief that the only tool a knowledge worker really needs, whether they are collaborating or not, is a computer. This over-reliance on computer screens for many tasks, combined with clean-desk policies, has impeded more visual ways of working such as sharing ideas or organising information (Gladwell, 2000; Smith, 2008). On each of the sites we visited during the research, we found evidence of people wanting to pin up papers and lay things out. Corridor walls, windows and even computer screens were all being used as surfaces to facilitate work in this more visual and creative way. Connectors, in their constant exchanges with people from around the company, often have a particular need to work more freely and visually than their surroundings currently allow (see Figure 5).

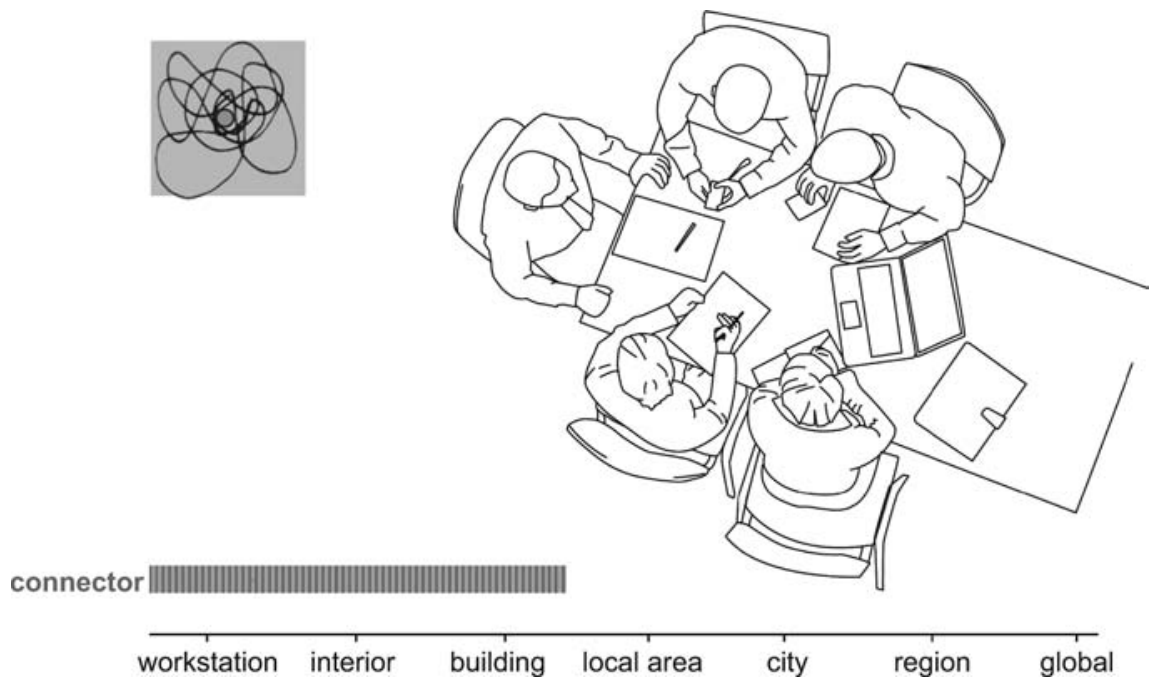

Space for thought

25
Figure 5. Connector 
$\mathrm{F}$

$29,1 / 2$

26

\section{The Gatherer}

The third character, the Gatherer, relies on many relationships generated away from the office. Spending around half the week away from the office at different appointments, the Gatherer can be found at client or customer offices, at other sites or using neutral third space locations such as cafés or members clubs. It is more likely that they will travel regionally than globally - the office remains a central fulcrum in their week. To the office, the Gatherer brings back information, business and important new relationships.

Technology has better enabled work in this way. The Gatherer communicates continually on the move through mobile and wireless technologies. As a resource, the office is important as a place where they can distill, process and review information on their own or face-to-face with relevant colleagues. Hence, they need to be provided with a combination of spaces allowing effective concentration and collaboration.

Managers recognise that work of this type means that they are more likely to be on the move and in many organisations, the Gatherer is no longer allocated their own desk. Instead they work on a shared-desk or hot-desk basis when they are in the office. This has considerable benefits in terms of space utilisation and is cost efficient. However the provision of poorly designed hot-desks has meant that many Gatherers simply take work home in the laptop bag (see Figure 6):

It's about planning not to be interrupted, a conscious choice, to work at home [...]

\section{The Navigator}

The fourth typology incorporates a range of different types of knowledge worker who are all, to a certain extent, visitors to their own office. Rarely in the office at all, the Navigator works for the organisation at arm's length. The group includes the

Figure 6. Gatherer
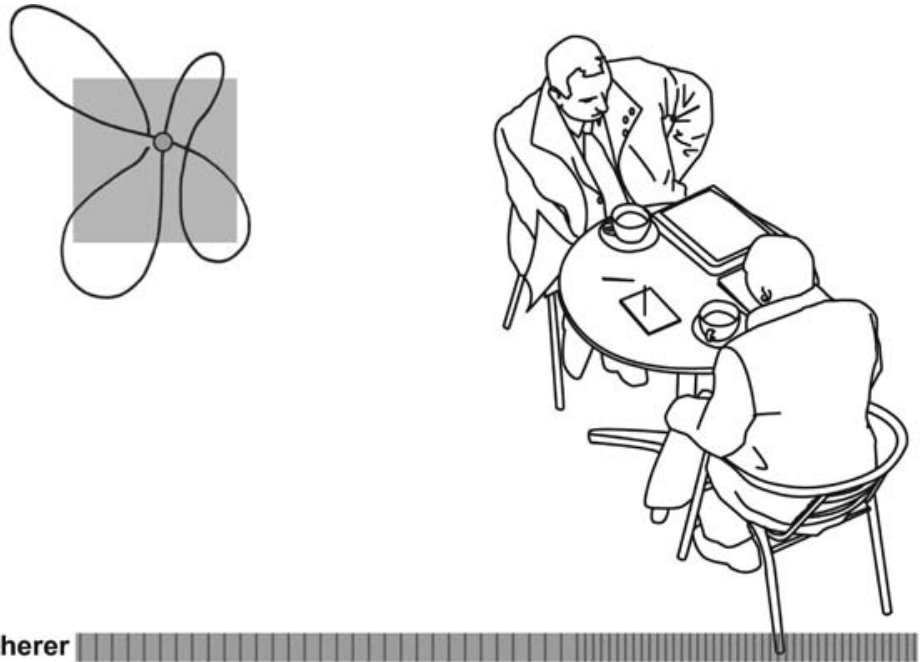

gatherer building local area city

region global


contractor who is employed on a project basis, the nomad salesman who attends the office a few times a month, and the consultant who arrives for a meeting and needs access to a space where they can sit down and use their laptop. Whilst this group is becoming increasingly common, it is also the group of knowledge workers that facilities managers know least about and are finding most difficult to provide for.

This is partly due to Navigators not sitting well in established hierarchies, and also because they don't sit at their desks, making it harder at a glance to measure their contribution. For the Navigator, the office is just a node within their network. They may spend less than a day a week at the office but it is important that they are not made to feel like an unwanted guest - they must be made comfortable and able to get on with the work they need to do immediately.

Navigators are often key figures within the organisation, holding large portfolios of responsibility and ambassadorial or highly valued international roles. Yet their design needs have yet to be adequately addressed. Asked whether she felt welcome, one highly qualified Navigator told us (see Figure 7):

No, it's generally, who is that consultant over there?

\section{Implications}

\section{Complex set of requirements}

The four typologies that we identified reflect the changing nature of knowledge work. The Anchor is in one sense a throwback to the process-driven floor plans of the twentieth century office-factory; the Navigator, enabled by new communication technologies, anticipates a more flexible and non-territorial future. With most knowledge workers still operating as Anchors and Connectors within office buildings, Gatherers and Navigators point towards a new territory for design in which more occasional and random presence within the work environment must nevertheless be catered for in an inclusive way.
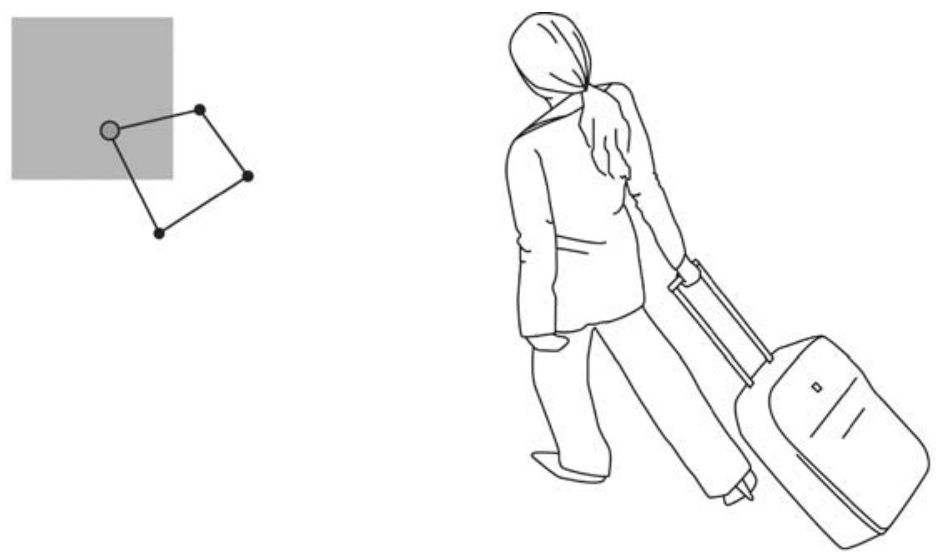

navigator

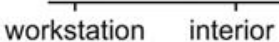

building

local area

city

region

global

Figure 7. Navigator
Space for thought

27 
$\mathrm{F}$

$29,1 / 2$

28

Considering some of these needs - the Anchor's requirement for comfort, the Connector's use of different spaces, the Gatherer's reliance on networks, and the Navigator's need to feel welcome - we are faced with a very complex set of requirements. If we take these as our premise for the design brief, we must go beyond the traditional remit of office design.

No longer is it enough to provide knowledge workers with open plan space, ergonomic furniture and the latest technology, the standard formula of the past decade. With all four typologies found in a single organisation, this wide range of needs requires a far more innovative and integrated approach. We must instead start to consider the office as a complete service - a landscape of workplaces, both physical and virtual. Providing for all four characters might seem like a challenge, but by describing the knowledge worker in this way it enables us to plan how they might overlap within this landscape, when they are likely to be absent, where they need to interact and when they need to be left alone, thus allowing a smarter, more effective planning of the space.

\section{A responsive environment}

The four typologies suggest that knowledge workers are both creative and individual in the way they work and demonstrate the need for more choice and control in the services available at the office. Knowledge workers need spaces and tools that can be adjusted to individual preference and the task in hand. In our study all four types of knowledge workers expressed difficulties with concentration and a lack of appropriate settings to facilitate solo working.

The introduction of permeable boundaries, such as curtains or screens that are easy to move and adjust, at the desk or in social spaces, could provide the privacy and quiet for such activities when necessary. Similarly, such vertical boundaries could provide surfaces for non-computer work, empowering Connector-style knowledge workers to work more freely and visually by pinning up and displaying artifacts.

\section{Developing new protocols}

With the work environment occupied in a much more transient and fluid way, there is a need to develop new cultural protocols that signal how people can use the office. How do Navigators orientate themselves on arrival and what new protocols can be developed to allow an intuitive understanding of how the space is occupied and used day to day? Perceptions of the "hot-desk" also need to be changed; in the drive to create efficient use of space, hot-desking is a practical solution but it tends to deliver a compromised and inadequate space to Gatherers and Navigators, who are among the most experienced and important players in the organisation. With a higher value placed on the hot-desk, people would feel more comfortably able to get on with work in the office rather than spending time seeking alternative spaces outside the office building.

\section{Conclusion}

Within the limitations of this small study, the development of these four typologies opens up new possibilities for the way we address the challenge of designing for knowledge workers. The generic use of the term "knowledge worker" has resulted in a generic approach to the way knowledge workers are provided for. More practical 
research needs to be done to understand the different rhythms and themes within knowledge work. We believe that the titles Anchor, Connector, Gatherer and Navigator allow a better understanding of the many different ways of working, within a more creative context. The attributes and characteristics of each group, offering a broader view of their respective needs, should help us to plan workspaces in the future that are responsive to these needs and intelligent in their use of resources.

In our research, there was often a discrepancy between what typology people felt they belonged to and the type they aspired to be. Many people felt that their workplace was designed in such a way as to leave them no option but to conform to a particular typology:

I am an Anchor, but I would prefer to be a much more agile type of worker.

If organisations are serious about raising knowledge worker productivity then perhaps consideration of these typologies (as well as others generated by other researchers) would enhance the shaping of a fuller brief for design. As a tool for creative, knowledge-led companies, it might be useful to ask their employees, first what typology they think are, and second what type they aspire to be, in this way promoting a debate about optimum ways of working and the facilities required to make it happen.

\section{References}

Davenport, T.H. (2005), Thinking for a Living: How to Get Better Performance and Results from Knowledge Workers, Harvard Business Press, Cambridge, MA.

Davenport, T.H., Thomas, R.J. and Cantrell, S. (2002), "The mysterious art and science of knowledge-worker performance", MIT Sloan Management Review, Fall, pp. 23-30.

Drucker, P. (1999), "Knowledge worker productivity: the biggest challenge", California Management Review, Vol. 41, Winter, pp. 79-94.

Duffy, F. (2005), The Impact of Office Design on Business Performance, Commission for Architecture and the Built Environment and British Council for Offices, London.

Duffy, F., Jaunzens, D., Laing, A. and Willis, S. (1998), "New environments for working: the re-design of offices and environmental systems for new ways of working", Construction Research Communication, London.

Erlich, A. and Bichard, J. (2008), “The welcoming workplace: designing for ageing knowledge workers", Journal of Corporate Real Estate, Vol. 10 No. 4, pp. 273-85.

Gensler (2008), "Workplace survey", available at: www.gensler.com/../2008_US_Workplace_ Survey_10_21_2008.pdf (accessed 12 March 2009).

Gladwell, M. (2000), "Designs for working: why your bosses want to turn your new office into Greenwich Village", The New Yorker, 11 December.

Jorgensen, B. (2003), "Baby boomers, Gen X and Gen Y? Policy implications for defense forces in the modern era", foresight, Vol. 5 No. 4, pp. 41-9.

Myerson, J. and Ross, P. (2006), Space to Work; New Office Design, Laurence King Publishing, London.

Smith, J. (2008), Welcoming Workplace: Designing Office Space for an Ageing Workforce in the 21st Century Knowledge Economy, Helen Hamlyn Centre, Royal College of Art, London.

Steelcase (2006), "Millennials make their mark", available at: www.steelcase.com/na/generations_ at_work_Research.aspx?f=17642) (accessed 6 November 2008). 
Veda, Q. (2006), “Using data-driven solutions to meet changing workspace needs”, white paper, Intel Corporation, March.

Wong, M., Gardiner, E., Lang, W. and Coulon, L. (2008), “Generational differences in personality and motivation: do they exist and what are the implications for the workplace?", Journal of Managerial Psychology, Vol. 23 No. 8, pp. 878-90.

About the authors

C. Greene graduated from the National College of Art and Design in Dublin with a degree in Textile Design (2004). Moving to London, she worked as a project manager before following this up with an MA in Design Products from the Royal College of Art (2007). Since then she has worked with Professor Jeremy Myerson at the Helen Hamlyn Centre, RCA as a Research Associate on a number of workplace projects related to demographic and technological change. Catherine Greene is the corresponding author and can be contacted at: catherine.greene@network.rca.ac.uk

J. Myerson is Director of the Helen Hamlyn Centre at the Royal College of Art, London, where he holds the Helen Hamlyn Chair of Design. A journalist, academic and activist in design for the past 30 years, he founded DesignWeek magazine in the UK and also the Royal College of Art's network for business, InnovationRCA. He is an active researcher and the author of many books on workplace design; his latest publication, New Demographics New Workspace, was published in Spring 2010 by Gower.

To purchase reprints of this article please e-mail: reprints@emeraldinsight.com Or visit our web site for further details: www.emeraldinsight.com/reprints 